Article

\title{
Wavelength-Tunable and Water-Stable Cesium-Lead-Based All-Bromide Nanocrystal-Polymer Composite Films Using Ultraviolet-Curable Prepolymer as an Anti-Solvent
}

\author{
Wook Hyun Kim ${ }^{1}$, Jungyoun Bae ${ }^{1,2}$, Kang-Pil Kim ${ }^{1}$ and Sungho Woo ${ }^{1, *}$ \\ 1 Division of Energy Technology, Daegu Gyeongbuk Institute of Science and Technology (DGIST), \\ 333 Techno Jungang-daero, Dalseong-gun, Daegu 42988, Korea; kwh1980@dgist.ac.kr (W.H.K.); \\ bjy9606@knu.ac.kr (J.B.); kkp@dgist.ac.kr (K.-P.K.) \\ 2 Department of Chemical Engineering, Kyungpook National University, 80 Daehak-ro, Buk-gu, \\ Daegu 41566, Korea \\ * Correspondence: shwoo@dgist.ac.kr
}

check for updates

Citation: Kim, W.H.; Bae, J.; Kim, K.-P.; Woo, S. Wavelength-Tunable and Water-Stable Cesium-LeadBased All-Bromide NanocrystalPolymer Composite Films Using Ultraviolet-Curable Prepolymer as an Anti-Solvent. Polymers 2022, 14, 381 https://doi.org/10.3390/ polym14030381

Academic Editors: Chunfu Zhang and $\mathrm{He} \mathrm{Xi}$

Received: 24 November 2021

Accepted: 17 January 2022

Published: 19 January 2022

Publisher's Note: MDPI stays neutral with regard to jurisdictional claims in published maps and institutional affiliations.

Copyright: (C) 2022 by the authors. Licensee MDPI, Basel, Switzerland. This article is an open access article distributed under the terms and conditions of the Creative Commons Attribution (CC BY) license (https:// creativecommons.org/licenses/by/ $4.0 /)$.

\begin{abstract}
All-inorganic metal halide perovskite nanocrystals (IPeNCs) have become one of the most promising luminescent materials for next-generation display and lighting technology owing to their excellent color expression ability. However, research on IPeNCs with stable blue emission is limited. In this paper, we report stable blue emissive all-bromide IPeNCs obtained through a modified ligandassisted reprecipitation method using an ultraviolet (UV)-curable prepolymer as the anti-solvent at a low temperature. We found that the blue emission originates from quantum-confined $\mathrm{CsPbBr}_{3}$ nanoparticles formed together with the colorless wide-bandgap $\mathrm{Cs}_{4} \mathrm{PbBr}_{6}$ nanocrystals. When the temperature of the prepolymer was increased from 0 to $50{ }^{\circ} \mathrm{C}, \mathrm{CsPbBr}_{3}$ nanoparticles became larger and more crystalline, thereby altering their emission color from blue to green. The synthesized all-bromide blue-emitting IPeNC solution remained stable for over $1 \mathrm{~h}$. It also remained stable when it was mixed with the green-emitting IPeNC solution. By simply exposing the as-synthesized IPeNC-prepolymer solutions to UV light, we formed water-stable composite films that emitted red, green, blue, and white colors. We believe that this synthetic method can be used to develop color-emitting composite materials that are highly suitable for application as the color conversion films of full-color liquid crystal display backlight systems and lighting applications.
\end{abstract}

Keywords: cesium halide perovskite nanocrystals; blue emission; $\mathrm{CsPbBr}_{3} / \mathrm{Cs}_{4} \mathrm{PbBr}_{6}$; UV-curable prepolymer; anti-solvent; reprecipitation

\section{Introduction}

Recently, all-inorganic metal halide perovskite nanocrystals (IPeNCs) with a general formula of $\mathrm{CsPbX}_{3}\left(\mathrm{X}=\mathrm{Cl}^{-}, \mathrm{Br}^{-}, \mathrm{I}^{-}\right)$have attracted intense interest for next-generation light-emitting diodes (LEDs) and full-color displays owing to their outstanding optical properties, such as a tunable bandgap, high photoluminescence (PL) quantum yield, and narrow PL linewidths [1,2]. Ligand-assisted reprecipitation (LARP) and hot injection (HI) methods have been widely used to synthesize IPeNCs. The HI method has several obvious drawbacks for commercialization, such as the need for a high temperature, vacuum, and inert atmosphere. In contrast, LARP is a simpler approach that can be conducted under an air atmosphere at relatively low temperatures; thus, it is more convenient for large-scale production [3].

In LED and display applications, the three primary colors of red, green, and blue (RGB) are essential for the realization of full and wide color gamuts. However, the development of IPeNCs with bright, stable blue emission remains a key problem. To address this, four main strategies have been pursued to develop blue-emitting IPeNCs [4,5]. The most widely used approach is the use of a mixed $\mathrm{Br} / \mathrm{Cl}$ halide composition to obtain $\mathrm{CsPbBr}_{\mathrm{x}} \mathrm{Cl}_{3-\mathrm{x}}$ 
IPeNCs [2]. However, when these $\mathrm{Br} / \mathrm{Cl}$ mixed halide IPeNCs are exposed to light or an electrical potential, they undergo significant phase separation, which results in unavoidable color instability and decreased emission intensity. This phase separation is induced by their lattice mismatch, which is due to the difference in the atomic radii of $\mathrm{Cl}$ and $\mathrm{Br}$. The second method is doping small metal cations $\left(\mathrm{Mn}^{2+}, \mathrm{Sn}^{2+}, \mathrm{Cd}^{2+}, \mathrm{Zn}^{2+}, \mathrm{Cu}^{2+}, \mathrm{Al}^{3+}, \mathrm{Nd}^{3+}\right.$, $\mathrm{Bi}^{3+}, \mathrm{Sb}^{3+}$ ) into $\mathrm{Pb}$ sites to distort the lattice or tilt the $\mathrm{PbBr}_{6}$ octahedra (or both), thereby shifting the PL emission to the blue region [6-11]. However, some dopants generate dual emissions, such as a blue region with an extra region from the doped cations. Another strategy is to impose a strong quantum confinement effect by reducing the radius of $\mathrm{CsPbBr}_{3} \mathrm{IPeNC}_{\mathrm{N}}$ to less than the exciton Bohr radius (approximately $7 \mathrm{~nm}$ for $\mathrm{CsPbBr}_{3}$ ). The fourth method is the synthesis of two-dimensional (2D) $\mathrm{CsPbBr}_{3}$ nanoplatelets that exhibit a quantum confinement effect. However, consistent fabrication is challenging for both quantum-confined nanocrystals (NCs) and 2D shapes owing to the phase transition from low-dimensional nanostructures to high-dimensional perovskites [12-16].

IPeNCs are unstable in water or polar solvents owing to their intrinsic ionic bonding, which is another key obstacle to their use in optoelectronic device applications. To overcome this issue, several studies have attempted to encapsulate IPeNCs using inorganic silica, $\mathrm{TiO}_{2}$, a mesoporous alumina structure, organic ligands, and polymer matrix materials [17-20]. Recently, IPeNCs have been composited with polymers to enhance their stability against moisture, light, and heat. Compared with other techniques, blending IPeNCs with a commercial polymer, such as polymethylmethacrylate, poly(laurylmethacrylate), polydimethylsiloxane, polystyrene, poly(styrene-ethylene-butylene-styrene), and thermoplastic polyurethane, is a relatively easy and effective method for protecting IPeNCs [21-27]. However, during the time-consuming blending process in air, IPeNCs often decompose and agglomerate owing to the large difference in the polarity between the IPeNCs and polymers. Hence, in situ synthesis strategies using ultraviolet (UV)-curable prepolymers as solvents or ligands to prevent the IPeNCs from agglomerating within the polymer have been extensively studied [28-32].

In this study, for the first time, we develop emission-wavelength-tunable all-bromidebased IPeNC-polymer composite films obtained through a modified LARP synthesis method using a UV-curable prepolymer as the anti-solvent. The absorption spectral and Xray diffraction $(\mathrm{XRD})$ data showed that the nanoparticles synthesized using the prepolymer comprised $\mathrm{Cs}_{4} \mathrm{PbBr}_{6}$ and $\mathrm{CsPbBr}_{3} \mathrm{NCs}$. In addition, a blue luminescent solution of these all-bromide NCs synthesized from the prepolymer was stable for more than $1 \mathrm{~h}$. Moreover, after being mixed with a green luminescent $\mathrm{CsPBBr}_{3}$ solution, the mixture exhibited stable blue and green luminescence peaks, which remained discrete and did not merge for more than $1 \mathrm{~h}$. After UV curing, the IPeNC-polymer composite films not only provided an adjustable emission color from blue $(465 \mathrm{~nm})$ to green $(515 \mathrm{~nm})$ without the introduction of mixed anion composition but also exhibited high stability in water. Therefore, we believe that our all-bromide-based IPeNC-polymer composite films have high potential for the color conversion film of liquid crystal display (LCD) backlight systems and lighting applications.

\section{Materials and Methods}

\subsection{Materials}

Lead bromide $\left(\mathrm{PbBr}_{2}, 99.999 \%\right)$, cesium bromide ( $\left.\mathrm{CsBr}, 99.999 \%\right)$, oleic acid (OA, technical grade, $90 \%$ ), dimethylformamide (DMF, anhydrous, 99.8\%), toluene (anhydrous, 99.8\%), benzyl methacrylate (BMA, 96\%), trimethylolpropane triacrylate (TMPTA), and a blend (50/50 wt.\%) of diphenyl(2,4,6-trimethylbenzoyl)phosphine oxide (TPO) and 2hydroxy-2-methylpropiophenone (HMPP) were purchased from Sigma-Aldrich (Saint Louis, MO, USA). Oleylamine (OAm, 95\%) was purchased from Strem (Newburyport, MA, USA). All chemicals were used as-received without further purification. The UV LED ( $395 \mathrm{~nm}, 10 \mathrm{~W})$ was purchased from JIN LED Co. (Seoul, Korea). 


\subsection{Preparation of the Precursors and Prepolymer}

The metal halide precursor solution was prepared by dissolving $0.2 \mathrm{mmol}$ of $\mathrm{CsBr}$ and $0.2 \mathrm{mmol}$ of $\mathrm{PbBr}_{2}$ in $5 \mathrm{~mL}$ of DMF solvent under vigorous stirring at $90^{\circ} \mathrm{C}$. Subsequently, $0.375 \mathrm{~mL}$ of $\mathrm{OA}$ and $0.25 \mathrm{~mL}$ of OAm were added to stabilize the precursor solution. Then, the solution was stirred at $90{ }^{\circ} \mathrm{C}$ to complete the dissolution prior to injecting it into the antisolvent. The UV-curable prepolymer was prepared by mixing BMA (monomer), TMPTA (crosslinker), and TPO/HMPP (photoinitiator) in volume fractions of 98:1:1.

\subsection{Synthesis of IPeNCs and Its Composite Films}

The IPeNCs were synthesized by the simple one-step LARP method first reported by Li et al. [3] with some modifications. Prior to injection, the precursor solution was heated to $90{ }^{\circ} \mathrm{C}$ to attain homogeneity, and the temperature of the anti-solvent (toluene or prepolymer) was maintained at 0,25 , or $50{ }^{\circ} \mathrm{C}$ using a temperature-controllable stirrer plate. Subsequently, $0.2 \mathrm{~mL}$ of the precursor solution at $90{ }^{\circ} \mathrm{C}$ was separately injected into $3 \mathrm{~mL}$ of the anti-solvent at 0,25 , or $50{ }^{\circ} \mathrm{C}$, under vigorous stirring for $10 \mathrm{~min}$ (Figure S1). Hereinafter, these synthesized solutions are labeled by the anti-solvent with a suffix indicating their temperature, namely, prepolymer-0, prepolymer-25, prepolymer-50, toluene- 0 , and toluene-25.

The prepared IPeNC-prepolymer solutions were each coated on a glass substrate and exposed to $365 \mathrm{~nm}$ UV light $(10 \mathrm{~mW})$ for $10 \mathrm{~min}$ to crosslink the BMA monomer, thereby forming an IPeNC-polymer composite film.

\subsection{Characterization and LED Color Measurements}

The UV-visible (UV-vis) absorption spectra were measured using a UV-3600 spectrophotometer (Shimadzu Co., Kyoto, Japan). The PL spectra were collected using an RF6000 spectrofluorophotometer (Shimadzu Co., Kyoto, Japan) at an excitation wavelength of $350 \mathrm{~nm}$. The PL quantum yields (PLQYs) of the samples were measured using an integrated sphere (FluoroMax-4, Horiba Scientific, Kyoto, Japan) at an excitation wavelength of $365 \mathrm{~nm}$. XRD patterns were recorded using an X'pert PRO diffractometer (PANalytical, Malvern, $\mathrm{UK}$ ) with $\mathrm{Cu} \mathrm{K} \alpha$ radiation (wavelength $=1.540 \AA$ ) to determine the crystal structure of the nanoparticles. A Rietveld refinement was performed to quantitatively analyze these patterns using the Highscore Plus software suite (PANalytical, Malvern, UK). Transmission electron microscopy (TEM) images were obtained using an FEI Technai G2 F20 TEM system (FEI, Hillsboro, OR, USA). A laboratory-made color measurement system equipped with a PR-670 spectrophotometer (Photo Research Co., North Syracuse, NY, USA) was used to measure the color coordinates and temperature. The dipole moment and molecular structure of BMA, toluene, and other chemicals were calculated by PM6 semi-empirical methods using the MOPAC2016 software $[33,34]$. The dipole moments are given in Debye units $\left(1 \mathrm{D}=3.334 \times 10^{-30} \mathrm{C} \cdot \mathrm{m}\right)$.

\section{Results and Discussion}

In the LARP method, the selection of suitable anti-solvents and injection temperature are two of the main factors that determine the crystal structure, size, and shape of the final IPeNCs. As shown in Figure 1a, the PL spectrum shifted from green $(513 \mathrm{~nm})$ to blue (465 nm) as the prepolymer (anti-solvent) temperature decreased. The measured PLQY values of prepolymer-0, prepolymer-25, prepolymer-50, and toluene- 25 are $29 \%, 57 \%, 38 \%$, and $40 \%$, respectively. These results indicate that blue-emitting (465 nm) IPeNCs with a PLQY of $29 \%$ were successfully synthesized by our modified LARP method using the prepolymer as the anti-solvent. 
(a)

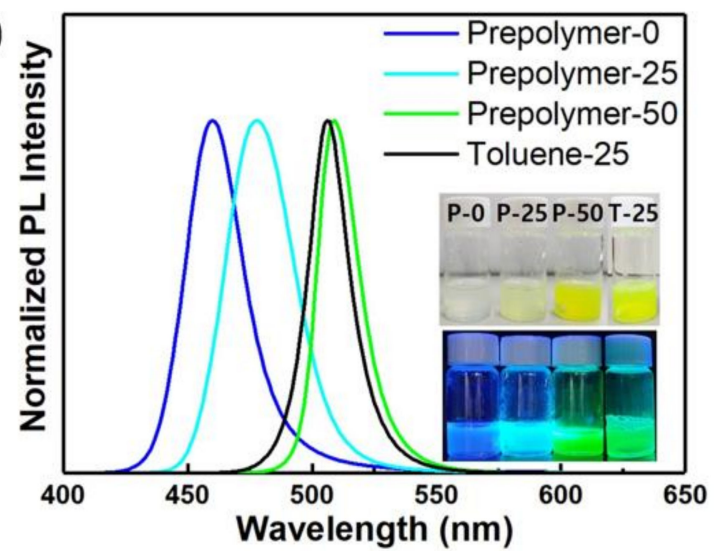

(b)

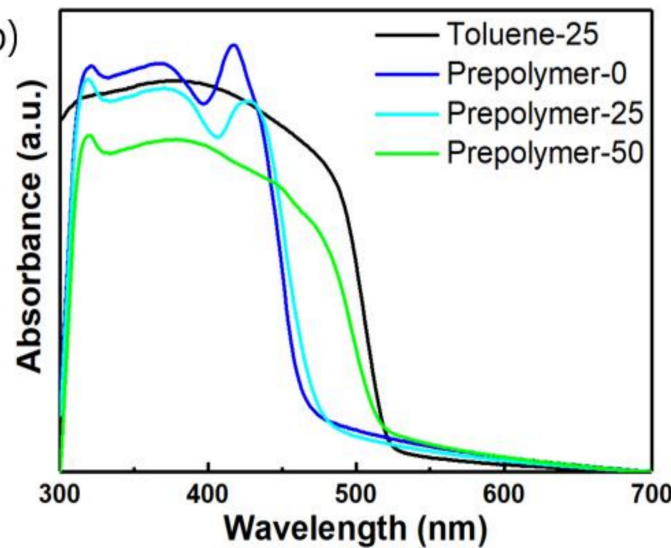

(c)

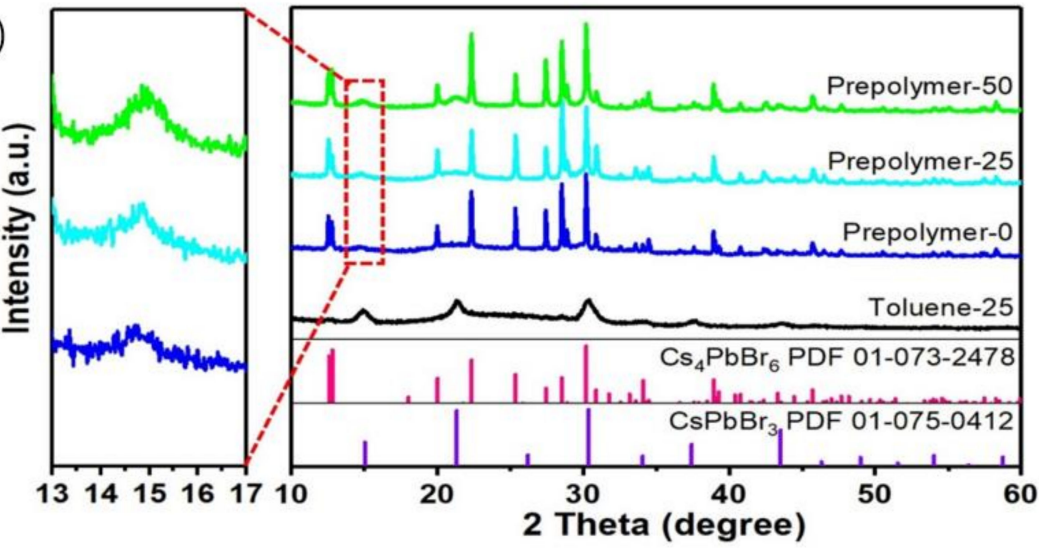

Figure 1. (a) Normalized photoluminescence (PL) spectra, (b) absorption spectra, and (c) X-ray diffraction (XRD) patterns of prepolymer-0, prepolymer-25, prepolymer-50, and toluene- 25 . The insets in (a) show images of the as-synthesized samples under ambient light (upper) and ultraviolet (UV) light (lower).

In Figure $1 b$, the distinct absorption peak at $314 \mathrm{~nm}$ indicates the formation of $\mathrm{Cs}_{4} \mathrm{PbBr}_{6}$ $\mathrm{NCs}$ when the metal halide precursor was injected into the prepolymer solution at $0{ }^{\circ} \mathrm{C}$ [35], whereas the excitonic absorption peak near $430 \mathrm{~nm}$ indicates the formation of quantumconfined $\mathrm{CsPbBr}_{3} \mathrm{NCs}$. In the case of prepolymer-25, the absorption peak at $430 \mathrm{~nm}$ shifted to a higher wavelength, and the absorption edge red-shifted. In prepolymer50 , the excitonic absorption peak disappeared, and the $\mathrm{CsPbBr}_{3}$ absorption edge shifted significantly to $515 \mathrm{~nm}$. Moreover, in toluene-25, the absorption peak of $\mathrm{Cs}_{4} \mathrm{PbBr}_{6}$ and the excitonic absorption peak of $\mathrm{CsPbBr}_{3}$ were not observed, and only the absorption edge of $\mathrm{CsPbr}_{3}$ at $515 \mathrm{~nm}$ was detected, which indicates that only the $\mathrm{CsPbBr}_{3}$ phase formed in the toluene system. This result is consistent with the trends in the XRD peaks shown in Figure $1 \mathrm{c}$ and the TEM images in Figure 2j-1. Specifically, the specific XRD peaks of $\mathrm{Cs}_{4} \mathrm{PbBr}_{6}$ and $\mathrm{CsPbBr}_{3}$ simultaneously appeared in the prepolymer system, whereas toluene-25 shows only the $\mathrm{CsPbBr}_{3}$ diffraction pattern [35-37]. Moreover, the XRD peak of the $\mathrm{Cs}_{4} \mathrm{PbBr}_{6}$ phase was more intense than that of the $\mathrm{Cs}_{5} \mathrm{PbBr}_{3}$ phase in the prepolymer system, indicating that $\mathrm{Cs}_{4} \mathrm{PbBr}_{6}$ crystals were larger than the $\mathrm{CsPbBr}_{3}$ crystals. In addition, the weak, broad XRD peak of $\mathrm{CsPBr}_{3}$ at approximately $15^{\circ}$ in the prepolymer-0 sample indicates that the $\mathrm{CsPbBr}_{3}$ phase was nearly amorphous with extremely small grains, as confirmed by the TEM images in Figure 2c [3]. Thus, the IPeNCs in prepolymer- 0 were approximately $4 \mathrm{~nm}$ in size and existed in a nearly amorphous phase. In addition, the $\mathrm{CsPbBr}_{3}$ diffraction peak intensified with the increase in the prepolymer temperature, implying that the $\mathrm{CsPbBr}_{3}$ nanoparticles grew larger with the increasing prepolymer temperature, as shown in Figure 2a-i. Figure S3 shows the particle size distribution of the $\mathrm{CsPbBr}_{3}$ nanoparticles measured from the TEM image in Figure 2. The average particle 
sizes of the $\mathrm{CsPbBr}_{3}$ nanoparticles in prepolymer-0, prepolymer-25, prepolymer-50, and toluene- 25 were $3.4,6.2,10.2$, and $10.1 \mathrm{~nm}$, respectively. A Rietveld refinement was applied to the XRD data shown in Figure 1c to calculate the compositional ratio of $\mathrm{Cs}_{4} \mathrm{PbBr}_{6}$ to $\mathrm{CsPbBr}_{3}$ in each sample (see Figure S4 and Table S1), which confirmed the coexistence of $\mathrm{Cs}_{4} \mathrm{PbBr}_{6}$ and $\mathrm{CsPbBr}_{3}$ as the major and minor components in the prepolymer system, respectively. In contrast, toluene- 25 consisted of only $\mathrm{CsPbBr}_{3}$ nanoparticles. In addition, the proportion of $\mathrm{CsPbBr}_{3}$ slightly increased as the setting temperature of the prepolymer increased, which is consistent with the increase in the crystallinity of $\mathrm{CsPbBr}_{3}$ nanoparticles with the increasing setting temperature. Moreover, $\mathrm{Cs}_{4} \mathrm{PbBr}_{6}$ is known to exhibit no obvious absorption or emission in the visible light region, because it has a wide bandgap of $3.9 \mathrm{eV}$ [35-37].
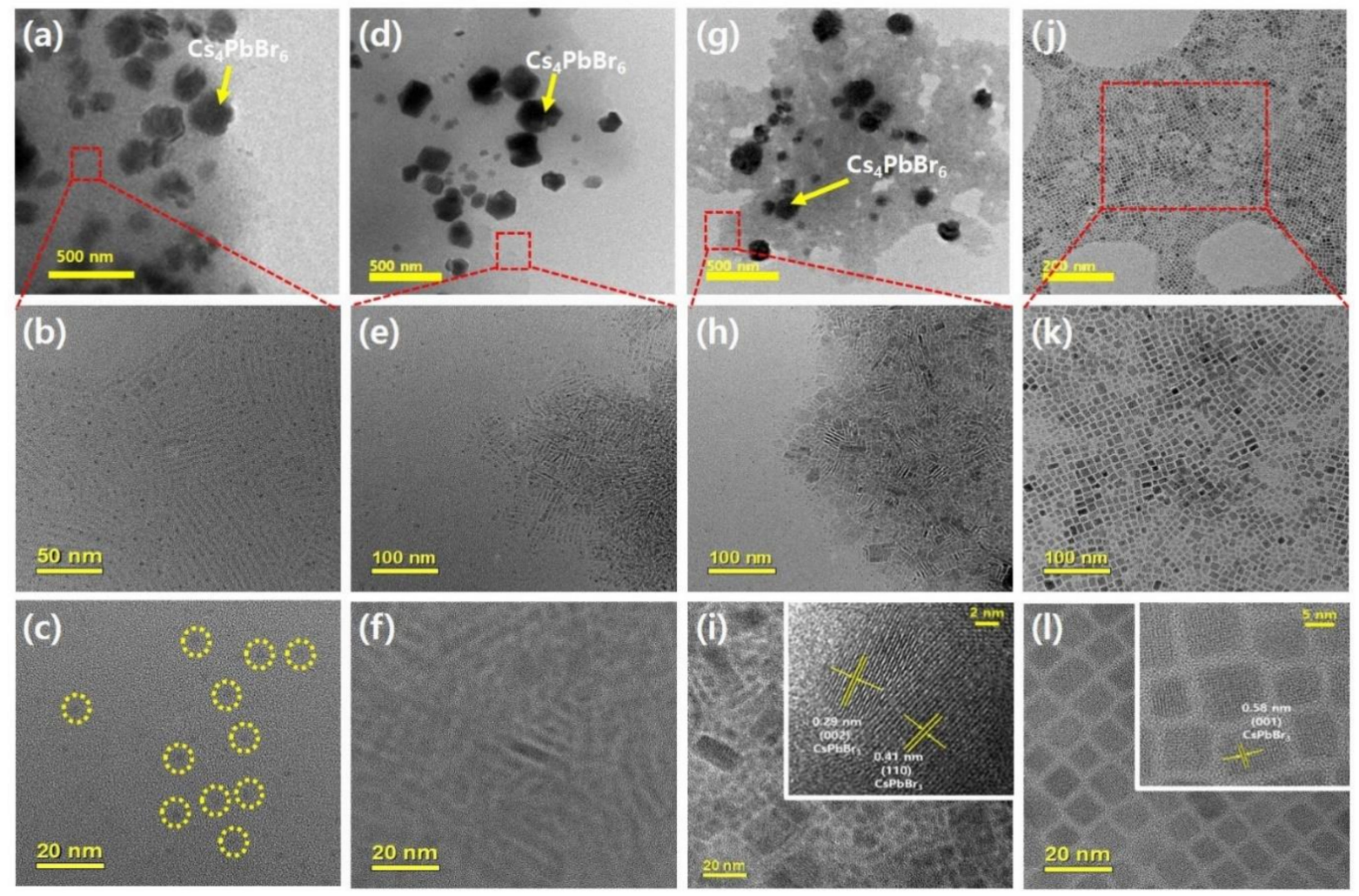

Figure 2. Transmission electron microscopy (TEM) images of the all-inorganic metal halide perovskite nanocrystals (IPeNCs) in (a-c) prepolymer-0, (d-f) prepolymer-25, (g-i) prepolymer-50, and $(\mathbf{j}-\mathbf{1})$ toluene-25. (a,d, $\mathbf{g}, \mathbf{j})$ are low-magnification images, and $(\mathbf{b}, \mathbf{c}, \mathbf{e}, \mathbf{f}, \mathbf{h}, \mathbf{i}, \mathbf{k}, \mathbf{l})$ are enlarged images of the $\mathrm{CsPbBr}_{3}$ nanoparticles. The yellow dotted circles in (c) indicate small amorphous $\mathrm{CsPbBr}_{3}$ nanoparticles. The insets in $(\mathbf{i}, \mathbf{j})$ show the lattice constants of $\mathrm{CsPbr}_{3}$ nanoparticles.

Based on these results, the blue emission of prepolymer- 0 originates from the quantumconfined amorphous $\mathrm{CsPBBr}_{3}$ nanoparticles, as described in previous reports [7,37]. To further investigate the formation mechanism of the $\mathrm{Cs}_{4} \mathrm{PbBr}_{6}$ nanoparticles in the prepolymer system, we focused on the difference in the solubility of $\mathrm{PbBr}_{2}$ between the prepolymer and toluene. The BMA monomer, which is a major component of the prepolymer system, is more polar than toluene (Figure S2), as evidenced by the dipole moments of their chemical structures of 2.173 and $0.516 \mathrm{D}$, respectively. This suggests stronger interactions between $\mathrm{PbBr}_{2}$ and the BMA monomer and higher solubility of $\mathrm{PbBr}_{2}$ in the monomer than those between $\mathrm{PbBr}_{2}$ and toluene, which exhibited weaker interactions and caused high precipitation, as shown in Figure 3a. As illustrated in Figure 3b,c, the difference in the solubility of $\mathrm{PbBr}_{2}$ in the prepolymer-DMF system was significantly smaller than that in toluene-DMF, whereas CsBr exhibited extremely low solubility in both the prepolymer 
and toluene. Therefore, when a precursor was dropped into the prepolymer anti-solvent, a relatively small amount of $\mathrm{PbBr}_{2}$ was precipitated from the prepolymer, whereas $\mathrm{CsBr}$ was mostly precipitated, resulting in the formation of $\mathrm{Cs}_{4} \mathrm{PbBr}_{6}$, which is a $\mathrm{PbBr}_{2}$ deficient phase, as the major component. The remaining $\mathrm{CsBr}$ and $\mathrm{PbBr}_{2}$ formed small amorphous $\mathrm{CsPbBr}_{3}$ nanoparticles, resulting in a blue emission. When the prepolymer temperature increased, the particle size of $\mathrm{CsPbBr}_{3}$ gradually increased to emit green light owing to the increased reaction rate. In contrast, as the solubility of $\mathrm{PbBr}_{2}$ and $\mathrm{CsBr}$ is extremely low in toluene, $\mathrm{CsPbBr}_{3}$ was mainly formed by maintaining the initial molar ratio of $1: 1$. Hence, $\mathrm{Cs}_{4} \mathrm{PbBr}_{6}$ can be easily generated in the prepolymer system containing BMA monomer.

(a)

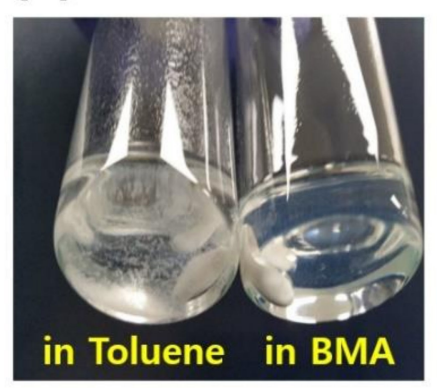

(b)

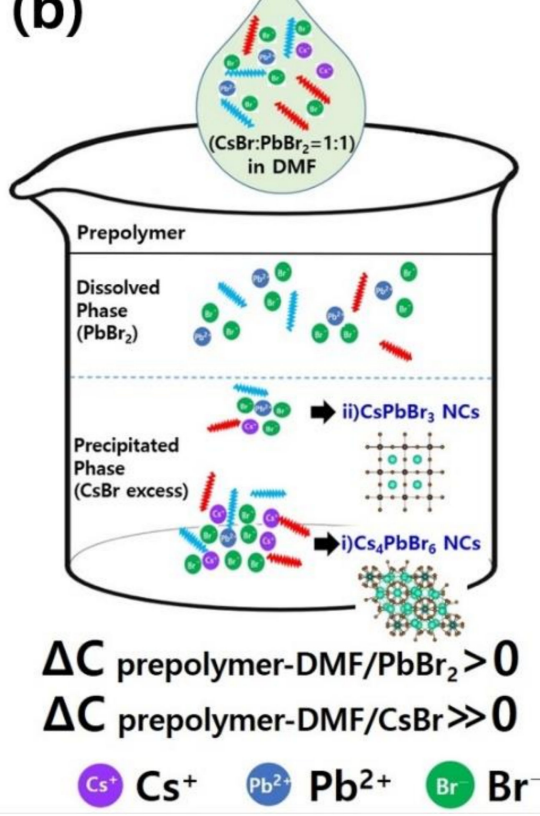

(c)

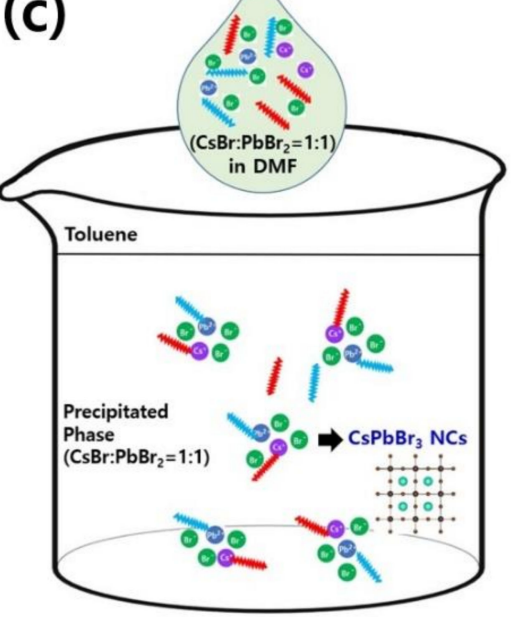

$\Delta \mathrm{C}$ Toluene-DMF/ $\mathrm{PbBr}_{2} \gg 0$

$\Delta \mathrm{C}$ Toluene-DMF/CsBr $\gg 0$

питим OA пимин OAm

Figure 3. (a) Solubility test with $0.2 \mathrm{~mL}$ of the $\mathrm{PbBr}_{2}$-dimethylformamide (DMF) solution (0.2 mmol of $\mathrm{PbBr}_{2}$ in $5 \mathrm{~mL} \mathrm{DMF}$ ) dropped into $5 \mathrm{~mL}$ of toluene or BMA solvent. Schematic of the formation mechanism for $\mathrm{Cs}_{4} \mathrm{PbBr}_{6}$ and $\mathrm{CsPbBr}_{3}$ in the (b) prepolymer and (c) toluene anti-solvent systems.

The small $\mathrm{CsPbBr} 3$ NCs with blue PL emission are expected to be unstable owing to their large surface area [38]. This instability allows them to easily aggregate into large particles, thus redshifting their PL spectrum and giving rise to green emission, such as that for the toluene system shown in Figure 4a. However, our prepolymer system maintained its blue PL well in the solution over $1 \mathrm{~h}$, as shown in Figure $4 \mathrm{~b}$, demonstrating the advantage of the prepolymer system. In addition, when the blue and green luminescent prepolymerbased solutions were mixed, two separate PL peaks persisted for more than $1 \mathrm{~h}$, as shown in Figure 5a. This stability was induced by the fact that the blue and the green luminescent perovskite nanoparticles synthesized in this manner were both bromide compositions; thus, no ion exchange occurred between them. In contrast, upon mixing the two solutions of $\mathrm{CsPbBr}_{1.5} \mathrm{Cl}_{1.5}$ (blue) and $\mathrm{CsPbBr}_{3}$ (green) formed with toluene as the anti-solvent, their original peaks disappeared and merged into a new single peak at $490 \mathrm{~nm}$ owing to an anion exchange reaction between the two components (Figure $5 b$ ). This finding indicates the stability of the nanoparticles in maintaining their luminescent color even when the two solutions were mixed. Further, this demonstrates the higher potential of the prepolymer system in white-light or multicolor applications. 

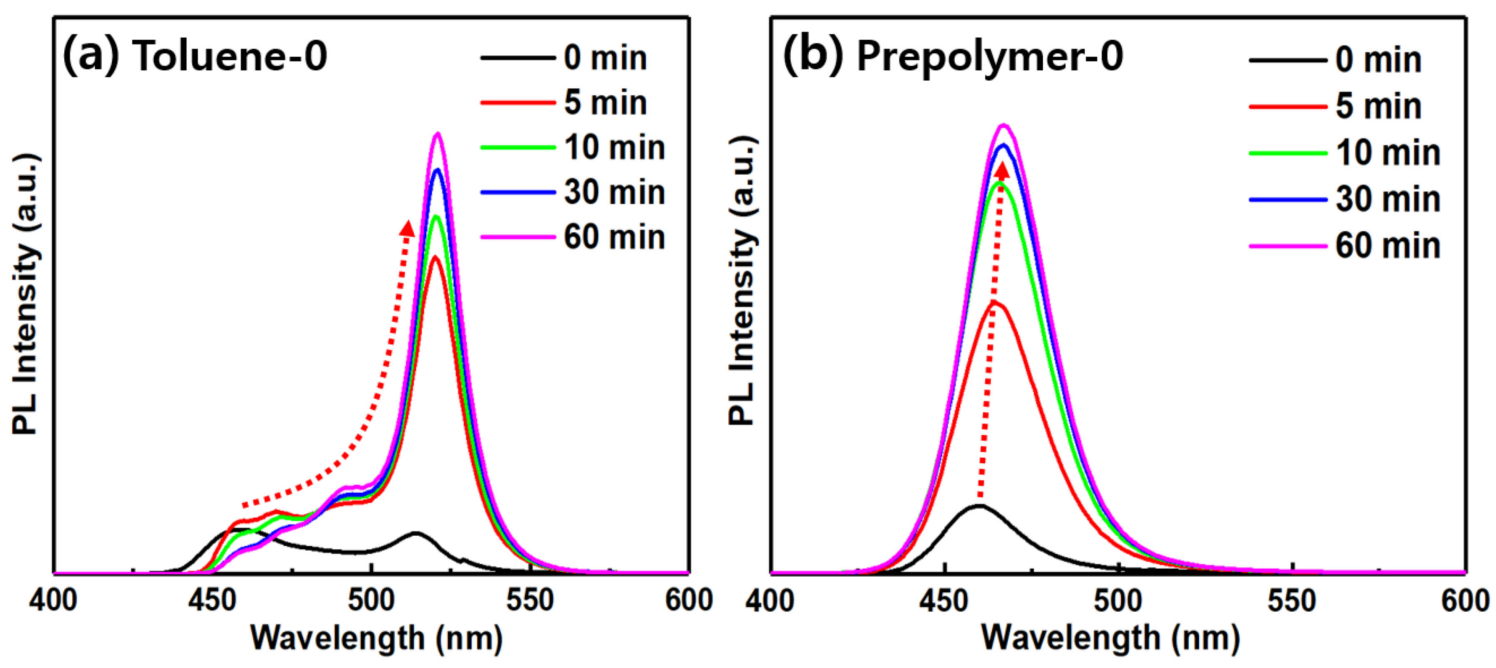

Figure 4. PL spectra as a function of reaction time after dropping in the precursor for the (a) toluene-0 and (b) prepolymer-0 samples.

(a)

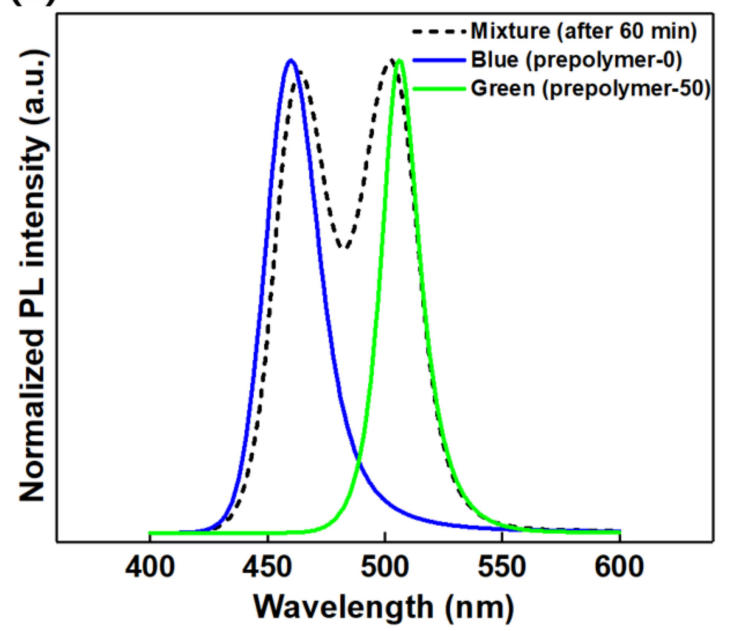

(b)

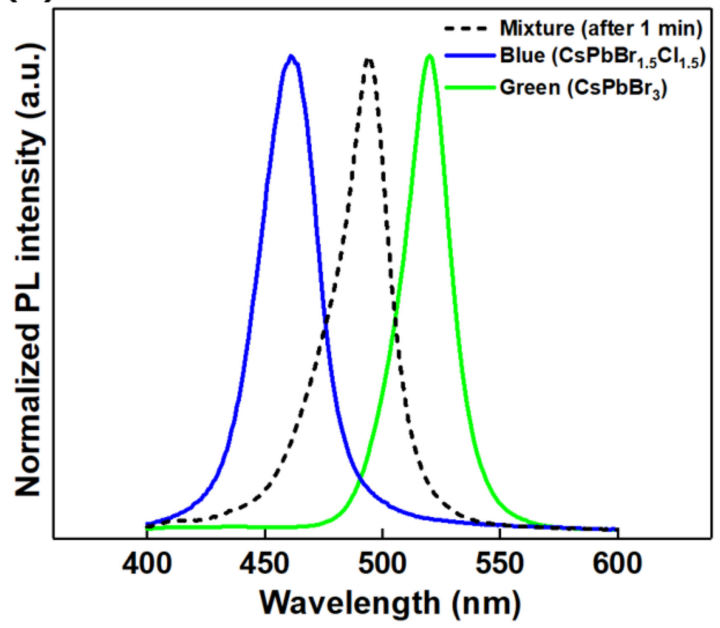

Figure 5. PL spectra for the color mixing tests of (a) prepolymer-0 (blue), prepolymer-50 (green), and a mixture of their solutions and (b) $\mathrm{CsPbBr}_{1.5} \mathrm{Cl}_{1.5}$ (blue) and $\mathrm{CsPbBr}_{3}$ (green) from the toluene anti-solvent and a mixture of their solutions.

To express the three primary colors of RGB using the prepolymer system, a $\mathrm{CsPbI}_{2} \mathrm{Br}$ (1:1 molar ratio of $\left.\mathrm{CsBr}: \mathrm{PbI}_{2}\right)$ precursor solution was injected into the prepolymer at temperatures of 40 and $50{ }^{\circ} \mathrm{C}$ to attain red emissions at 605 and $655 \mathrm{~nm}$, respectively, as shown in Figure 6a. Finally, the IPeNC-prepolymer solution was coated on a substrate and exposed to UV light to fabricate water-stable PL-emitting composite films. This simplicity of the fabrication process is significantly advantageous for the preparation of the UV-curable prepolymer systems. As shown in Figure 6b, letters of different colors were produced through UV crosslinking. The letters stably emitted their PL color even in a water bath at an ambient temperature of $23^{\circ} \mathrm{C}$, confirming the passivation effect of the acryl-based prepolymer system after full crosslinking. The ability to freely form the final shape and emission color of the composite products is another notable advantage of the UV-curable prepolymer systems for their applications. 
(a)

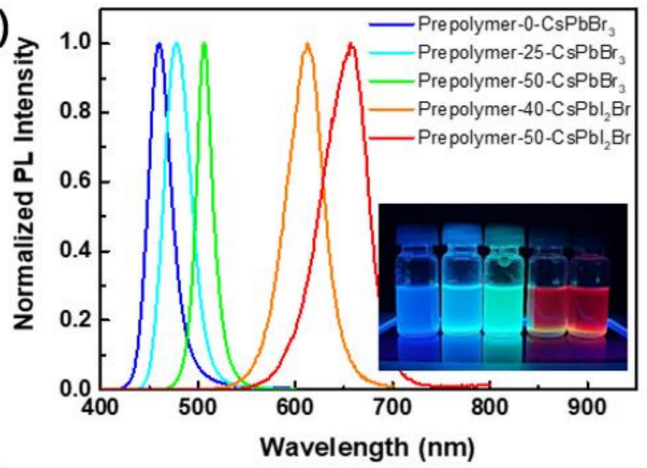

(b)

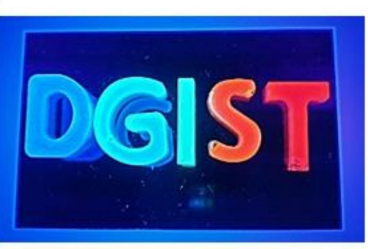

(c)

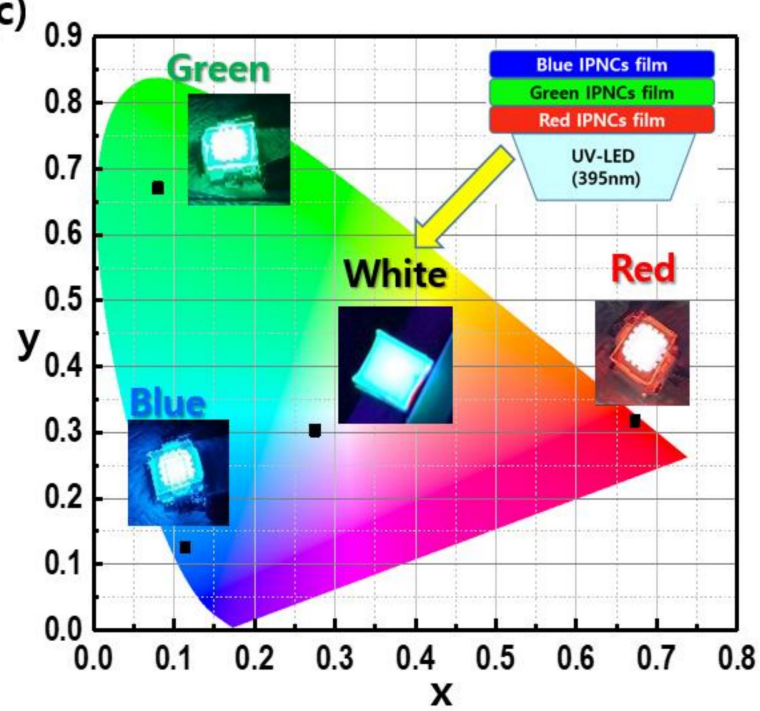

Figure 6. (a) Five different emission colors of the as-prepared IPeNC-prepolymer solutions and their PL spectra. (b) PL-emitting images of the prepared "DGIST" letters in ambient air (left) and in a water bath (right). (c) PL-emitting images of the color conversion films of red, green, blue, and white using a 395-nm UV light-emitting diode (LED), and their CIE color coordinates. The inset represents the configuration of the white LED device.

The IPeNCs are promising for display and lighting applications owing to their excellent optical properties $[7,39,40]$. RGB primary colors were well represented in the composite film state; thus, a wide color gamut of $98 \%$ of the National Television System Committee (NTSC) can be expressed, as shown in Figure 6c. A white-emitting film was fabricated by stacking the RGB color films on a $10 \mathrm{~W}$ UV LED. The correlated color temperature was $9700 \mathrm{~K}$. These results show that this simple approach can be used to fabricate a color conversion layer for LCD backlight units and lighting systems.

\section{Conclusions}

We developed a facile method for synthesizing color-tunable all-bromide based perovskite NCs through a modified LARP method using UV-curable prepolymer as the antisolvent. By controlling the prepolymer temperature, the PL color can be varied from blue to green without a $\mathrm{Cl}^{-}$anion exchange process. After an in-depth study, we concluded that the stable blue emission of the sample obtained with a prepolymer temperature of $0{ }^{\circ} \mathrm{C}$ originates from the quantum-confined $\mathrm{CsPbB}_{3}$ nanoparticles, which are nearly amorphous and approximately $4 \mathrm{~nm}$ in size. The selective solubility of the prepolymer to $\mathrm{PbBr}_{2}$ plays a key role in the formation of the all-bromide blue-emitting perovskite nanoparticles. Colorless, wide-bandgap $\mathrm{Cs}_{4} \mathrm{PbBr}_{6}$ nanoparticles with a $\mathrm{PbBr}_{2}$-deficient composition were initially generated owing to the selective solubility of the prepolymer. In addition, $\mathrm{CsPBBr}_{3}$ nanoparticles that had a radius smaller than the Bohr radius were formed, which emitted blue PL. Setting the temperature of the prepolymer higher increased both the size and crystallinity of $\mathrm{CsPBr}_{3}$ nanoparticles, leading to green emission.

In terms of color stability, the synthesized all-bromide blue-emitting IPeNC solution remained stable, and two separate luminescence peaks persisted for over $1 \mathrm{~h}$ when mixed with the green-emitting IPeNC solution. By coating the IPeNC-prepolymer solutions and exposing them to UV light, we easily obtained a water-stable nanocomposite film with high emission quality and high potential for application as a color conversion layer in wide color gamut LCD backlight units and lighting lamp system. 
Supplementary Materials: The following are available online at https: / www.mdpi.com/article / 10.3390 / polym14030381/s1, Figure S1: Schematic of the synthesis of IPeNCs through the modified LARP method; Figure S2: Molecular structure and calculated dipole moments of chemicals used in the prepolymer preparation and toluene; Figure S3: Particle size distributions of the $\mathrm{CsPbBr}_{3}$ nanoparticles in (a) prepolymer-0, (b) prepolymer-25, (c) prepolymer-50, and (d) toluene-25 samples; Figure S4: Rietveld refinement of X-ray diffraction patterns of (a) prepolymer-0, (b) prepolymer-25, (c) prepolymer-50, and (d) toluene-25; Table S1: Compositional ratio of the samples calculated from the Rietveld refinements of the XRD patterns.

Author Contributions: Conceptualization, W.H.K. and S.W.; methodology, W.H.K. and J.B.; formal analysis, W.H.K., J.B., K.-P.K. and S.W.; validation, W.H.K. and J.B.; data curation, S.W.; writingoriginal draft preparation, S.W.; writing-review and editing, K.-P.K.; visualization, W.H.K. and J.B.; supervision, S.W.; funding acquisition, S.W. All authors have read and agreed to the published version of the manuscript.

Funding: This work was funded by the National Research Foundation of Korea (NRF) grant funded by the Korean government (MSIT) (NRF-2019R1C1C1007569) and the DGIST R\&D Program of the Ministry of Science and ICT of Korea (21-ET-08).

Institutional Review Board Statement: Not applicable.

Informed Consent Statement: Not applicable.

Data Availability Statement: The data presented in this study are available on request from the corresponding author.

Acknowledgments: We would like to thank S.W. Cho and T.H. Cheon of the Center for Core Research Facilities (DGIST-CCRF) for the XRD and TEM analyses.

Conflicts of Interest: The authors declare no conflict of interest.

\section{References}

1. Huang, H.; Bodnarchuk, M.I.; Kershaw, S.V.; Kovalenko, M.V.; Rogach, A.L. Lead halide perovskite nanocrystals in the research spotlight: Stability and defect tolerance. ACS Energy Lett. 2017, 2, 2071-2083. [CrossRef]

2. Akkerman, Q.A.; Rainò, G.; Kovalenko, M.V.; Manna, L. Genesis, challenges and opportunities for colloidal lead halide perovskite nanocrystals. Nat. Mater. 2018, 17, 394-405. [CrossRef]

3. Li, X.; Wu, Y.; Zhang, S.; Cai, B.; Gu, Y.; Song, J.; Zeng, H. CsPbX 3 quantum dots for lighting and displays: Room-temperature synthesis, photoluminescence superiorities, underlying origins and white light-emitting diodes. Adv. Funct. Mater. 2016, 26, 2435-2445. [CrossRef]

4. Shi, H.; Zhang, X.; Sun, X.; Zhang, X. Deep blue emission of all-bromide-based cesium lead perovskite nanocrystals. J. Phys. Chem. C 2020, 124, 1617-1622. [CrossRef]

5. Peng, X.; Yan, C.; Chun, F.; Li, W.; Fu, X.; Yang, W. A review of low-dimensional metal halide perovskites for blue light emitting diodes. J. Alloys Compd. 2021, 883, 160727. [CrossRef]

6. Yang, D.; Huo, D. Cation doping and strain engineering of $\mathrm{CsPbr}_{3}$-based perovskite light emitting diodes. J. Mater. Chem. C 2020, 8, 6640-6653. [CrossRef]

7. Liu, M.; Zhong, G.; Yin, Y.; Miao, J.; Li, K.; Wang, C.; Xu, X.; Shen, C.; Meng, H. Aluminum-doped cesium lead bromide perovskite nanocrystals with stable blue photoluminescence used for display backlight. Adv. Sci. 2017, 4, 1700335. [CrossRef]

8. Bi, C.; Wang, S.; Li, Q.; Kershaw, S.V.; Tian, J.; Rogach, A.L. Thermally stable copper(II)-doped cesium lead halide perovskite quantum dots with strong blue emission. J. Phys. Chem. Lett. 2019, 10, 943-952. [CrossRef] [PubMed]

9. Dong, X.; Tsiwah, E.A.; Li, T.; Hu, J.; Li, Z.; Ding, Y.; Deng, Z.; Chen, W.; Xu, L.; Gao, P.; et al. Trivalent ion mediated abnormal growth of all inorganic perovskite nanocrystals and their divergent emission properties. Nanoscale 2019, 11, 7903-7912. [CrossRef] [PubMed]

10. Zhang, X.; Wang, H.; Hu, Y.; Pei, Y.; Wang, S.; Shi, Z.; Colvin, V.L.; Wang, S.; Zhang, Y.; Yu, W.W. Strong blue emission from $\mathrm{Sb}^{3+}$-doped super small CsPbBr 3 nanocrystals. J. Phys. Chem. Lett. 2019, 10, 1750-1756. [CrossRef]

11. Xie, Y.; Peng, B.; Bravic, I.; Yu, Y.; Dong, Y.; Liang, R.; Ou, Q.; Monserrat, B.; Zhang, S. Highly efficient blue-emitting CsPbBr 3 perovskite nanocrystals through neodymium doping. Adv. Sci. 2020, 7, 2001698. [CrossRef] [PubMed]

12. Jiang, M.; Hu, Z.; Liu, Z.; Wu, Z.; Ono, L.K.; Qi, Y. Engineering green-to-blue emitting $\mathrm{CsPbBr}_{3}$ quantum-dot films with efficient ligand passivation. ACS Energy Lett. 2019, 4, 2731-2738. [CrossRef]

13. Yang, H.; Feng, Y.; Tu, Z.; Su, K.; Fan, X.; Liu, B.; Shi, Z.; Zhang, Y.; Zhao, C.; Zhang, B. Blue emitting CsPbBr 3 perovskite quantum dot inks obtained from sustained release tablets. Nano Res. 2019, 12, 3129-3134. [CrossRef]

14. Xu, X.; He, H.; Fang, Z.; Lou, H.; Lin, C.; Chen, L.; Ye, Z. Ultrasonication-assisted ambient-air synthesis of monodispersed blue-emitting $\mathrm{CsPbBr}_{3}$ quantum dots for white light emission. ACS Appl. Nano Mater. 2019, 2, 6874-6879. [CrossRef] 
15. Tomanova, K.; Cuba, V.; Brik, M.G.; Mihokova, E.; Turtos, R.M.; Lecoq, P.; Auffray, E.; Nikl, M. On the structure, synthesis, and characterization of ultrafast blue-emitting $\mathrm{CsPbBr}_{3}$ nanoplatelets. APL Mater. 2019, 7, 011104. [CrossRef]

16. Shamsi, J.; Kubicki, D.; Anaya, M.; Liu, Y.; Ji, K.; Frohna, K.; Gray, C.P.; Friend, R.H.; Stranks, S.D. Stable hexylphosphonate-capped blue-emitting quantum-confined CsPbBr 3 nanoplatelets. ACS Energy Lett. 2020, 5, 1900-1907. [CrossRef] [PubMed]

17. Huang, H.; Chen, B.; Wang, Z.; Hung, T.F.; Susha, A.S.; Zhong, H.; Rogach, A.L. Water resistant CsPbX 3 nanocrystals coated with polyhedral oligomeric silsesquioxane and their use as solid state luminophores in all-perovskite white light-emitting devices. Chem. Sci. 2016, 7, 5699-5703. [CrossRef]

18. Wang, H.C.; Lin, S.Y.; Tang, A.C.; Singh, B.P.; Tong, H.C.; Chen, C.Y.; Lee, Y.C.; Tsai, T.L.; Liu, R.S. Mesoporous silica particles integrated with all-inorganic $\mathrm{CsPBBr}_{3}$ perovskite quantum-dot nanocomposites (MP-PQDs) with high stability and wide color gamut used for backlight display. Angew. Chem. Int. Ed. 2016, 55, 7924-7929. [CrossRef]

19. Hai, J.; Li, H.; Zhao, Y.; Chen, F.; Peng, Y.; Wang, B. Designing of blue, green, and red CsPbX 3 perovskite-codoped flexible films with water resistant property and elimination of anion-exchange for tunable white light emission. Chem. Commun. 2017, 53, 5400-5403. [CrossRef]

20. Lv, W.; Li, L.; Xu, M.; Hong, J.; Tang, X.; Xu, L.; Wu, Y.; Zhu, R.; Chen, R.; Huang, W. Improving the stability of metal halide perovskite quantum dots by encapsulation. Adv. Mater. 2019, 31, 1900682. [CrossRef]

21. Protesescu, L.; Yakunin, S.; Bodnarchuk, M.I.; Krieg, F.; Caputo, R.; Hendon, C.H.; Yang, R.X.; Walsh, A.; Kovalenko, M.V. Nanocrystals of cesium lead halide perovskites $\left(\mathrm{CsPb}_{3}, \mathrm{X}=\mathrm{Cl}, \mathrm{Br}\right.$, and I): Novel optoelectronic materials showing bright emission with wide color gamut. Nano Lett. 2015, 15, 3692-3696. [CrossRef]

22. Raja, S.N.; Bekenstein, Y.; Koc, M.A.; Fischer, S.; Zhang, D.; Lin, L.; Ritchie, R.O.; Yang, P.; Alivisatos, A.P. Encapsulation of perovskite nanocrystals into macroscale polymer matrices: Enhanced stability and polarization. ACS Appl. Mater. Interfaces 2016, 8, 35523-35533. [CrossRef]

23. Xu, L.; Chen, J.; Song, J.; Li, J.; Xue, J.; Dong, Y.; Cai, B.; Shan, Q.; Han, B.; Zeng, H. Double-protected all-inorganic perovskite nanocrystals by crystalline matrix and silica for triple-modal anti-counterfeiting codes. ACS Appl. Mater. Interfaces 2017, 9, 26556-26564. [CrossRef]

24. Wei, Y.; Deng, X.; Xie, Z.; Cai, X.; Liang, S.; Ma, P.; Hou, Z.; Cheng, Z.; Lin, J. Enhancing the stability of perovskite quantum dots by encapsulation in crosslinked polystyrene beads via a swelling-shrinking strategy toward superior water resistance. Adv. Funct. Mater. 2017, 27, 1703535. [CrossRef]

25. Yang, X.; Xu, T.; Zhu, Y.; Cai, J.; Gu, K.; Zhu, J.; Wang, Y.; Shen, J.; Li, C. Preparation of CsPbBr $3 @ P S$ composite microspheres with high stability by electrospraying. J. Mater. Chem. C 2018, 6, 7971-7975. [CrossRef]

26. Zhou, H.; Park, J.; Lee, Y.; Park, J.-M.; Kim, J.-H.; Kim, J.S.; Lee, H.-D.; Jo, S.H.; Cai, X.; Li, L.; et al. Water passivation of perovskite nanocrystals enables air-stable intrinsically stretchable color-conversion layers for stretchable displays. Adv. Mater. 2020, 32, 2001989. [CrossRef] [PubMed]

27. Shi, J.; Ge, W.; Gao, W.; Xu, M.; Zhu, J.; Li, Y. Enhanced thermal stability of halide perovskite $\mathrm{CsPbX}_{3}$ nanocrystals by a facile TPU encapsulation. Adv. Optical Mater. 2020, 8, 1901516. [CrossRef]

28. Zhu, L.; Yuan, S.; Cheng, J.; Chen, L.; Liu, C.; Tong, H.; Zeng, H.; Cheng, Q. Room temperature in-situ synthesis of inorganic lead halide perovskite nanocrystals sol using ultraviolet polymerized acrylic monomers as solvent and their composites with high stability. Appl. Sci. 2020, 10, 3325. [CrossRef]

29. Xin, Y.; Shen, W.; Deng, Z.; Zhang, J. Highly emissive and color-tunable perovskite cross-linkers for luminescent polymer networks. ACS Appl. Mater. Interfaces 2018, 10, 28971-28978. [CrossRef]

30. Tong, J.; Wu, J.; Shen, W.; Zhang, Y.; Liu, Y.; Zhang, T.; Nie, S.; Deng, Z. Direct hot-injection synthesis of lead halide perovskite nanocubes in acrylic monomers for ultrastable and bright nanocrystal-polymer composite films. ACS Appl. Mater. Interfaces 2019, 11, 9317-9325. [CrossRef]

31. Xin, Y.; Zhao, H.; Zhang, J. Highly stable and luminescent perovskite-polymer composites from a convenient and universal strategy. ACS Appl. Mater. Interfaces 2018, 10, 4971-4980. [CrossRef]

32. Sun, H.; Yang, Z.; Wei, M.; Sun, W.; Li, X.; Ye, S.; Zhao, Y.; Tan, H.; Kynaston, E.L.; Schon, T.B.; et al. Chemically addressable perovskite nanocrystals for light-emitting applications. Adv. Mater. 2017, 29, 1701153. [CrossRef]

33. Stewart, J.J.P. Optimization of parameters for semiempirical methods V: Modification of NDDO approximations and application to 70 elements. J. Mol. Mod. 2007, 13, 1173-1213. [CrossRef] [PubMed]

34. MOPAC2016. Available online: http:/ / openmopac.net/MOPAC2016.html (accessed on 20 October 2021).

35. Jing, Q.; Xu, Y.; Su, Y.; Xing, X.; Lu, Z. A systematic study of the synthesis of cesium lead halide nanocrystals: Does $\mathrm{Cs}_{4} \mathrm{PbBr}_{6}$ or $\mathrm{CsPbBr}_{3}$ form? Nanoscale 2019, 11, 1784-1789. [CrossRef] [PubMed]

36. He, M.; Wang, C.; Li, J.; Wu, J.; Zhang, S.; Kuo, H.-C.; Shao, L.; Zhao, S.; Zhang, J.; Kang, F.; et al. CsPbBr ${ }_{3}-\mathrm{Cs}_{4} \mathrm{PbBr}_{6} \mathrm{Composite}$ nanocrystals for highly efficient pure green light emission. Nanoscale 2019, 11, 22899-22906. [CrossRef] [PubMed]

37. Lu, H.; Tang, Y.; Rao, L.; Li, Z.; Ding, X.; Song, C.; Yu, B. Investigating the transformation of CsPbBr 3 nanocrystals into highly stable $\mathrm{CsPbBr}_{3} / \mathrm{Cs}_{4} \mathrm{PbBr}_{6}$ nanocrystals using ethyl acetate in a microchannel reactor. Nanotechnology 2019, 30, 295603. [CrossRef]

38. Gao, H.; Liu, S.; Xue, Z.; Liu, W.; Nie, Y.; Chen, G.; Li, X. Synthesis and photoluminescence properties of $\mathrm{CsPbBr}_{3}$ quantum dots by using para-xylene as the anti-solvent. J. Lumines. 2019, 215, 116584. [CrossRef] 
39. Adhikari, G.C.; Thapa, S.; Zhu, H.; Zhu, P. UV resin enhanced stability of metal halide perovskite nanocrystals for white light-emitting diodes. ACS Appl. Electron. Mater. 2020, 2, 35-40. [CrossRef]

40. Wang, X.; Bao, Z.; Chang, Y.-C.; Liu, R.-S. Perovskite quantum dots for application in high color gamut backlighting display of light-emitting diodes. ACS Energy Lett. 2020, 5, 3374-3396. [CrossRef] 